\title{
A Book Review: New Directions, Reading, Writing, and Critical Thinking
}

\author{
- Dipendra Kumar Khatri
}

\begin{abstract}
This article presents the review of the book that is prescribed for the Bachelor level course. The purpose of the particular review of the book is to highlight the strengths and weaknesses of the selected book. It is started with the general background of the writer of the book. Then, the objectives, contents are reviewed with other general features. Finally, it was found that maximum contents are selected from the Western World. So, it was concluded to include the texts from the Eastern World and add more pictures to develop critical thinking among the readers.
\end{abstract}

Key words: Review, Critical thinking, Intercultural communication, Eastern and Western World

\section{Introduction}

'New Directions: Reading, writing and Critical thinking' is a book written by Peter S. Gardner. $\mathrm{He}$ is a Professor in Microwave Engineering at the University of Birmingham. He has over 120 publications on various aspects of microwave engineering research. He teaches microwave engineering and communication systems engineering at Honours and Masters levels at Birmingham, and he regularly delivers course in microwave design at the CPD center in Oxford University .

The second edition of this book was published in 2005 in Cambridge by Cambridge University Press. It is theoretical book and reprinted in India; First south Asian Edition 2009 for sells only in Nepal with the cost of Rs 232. It contains 292 pages.

Title : New Directions: Reading, Writing and Critical Thinking Author: Peter S. Gardner

Publisher: Cambridge University Press

Year of Publication: 2005 (Second Edition)

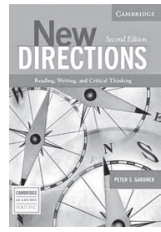




\section{A Book Review: New Directions, Reading, Writing, and Critical Thinking}

Price: Rs 232

Pages: 292

Reviewer: Dipendra Kumar Khatri

New Directions: Reading, Writing, and Critical Thinking is the book written for students who are studying, or preparing for study at an English speaking colleges or university. In the context of Nepal it is being used as the course book for the Bachelor level students: Faculty of Education Tribhuvan University majoring English and Faculty of Humanities. New Directions is a thematically based, interactive reader designed to help students meet the demands of reading and writing assignments in college and university classes. To elaborate this, the texts are supposed to offer a number of challenging reading and writing activities that encourage the higher -order thinking skills of analysis, synthesis, interpretation, evaluation, and application necessary for academic success.

\section{Contents Included in the Book}

This book consists of five thematically based chapters. Each of the chapters contains eight reading lessons. The first chapter deals with intercultural communication that explores cultural values, beliefs behaviors and the intercultural problems that sometimes resulted from those differences. It also deals about how people from diverse cultures regard time, express them verbally, and interact successfully. The reading lessons are: American values and assumptions by Gary Althen, Where do we stand? by Lisa Davis, Time talk with an accent by Robert Levine, Polite but thirsty by Yaping Tang, Friends and strangers by Margaret K.(Omar) Nydell, A coward by Premchand, The blind men and the elephant by John Godfrey Saxe and humor and cartoon. The second chapter deals with education that explores the major goals of education, the problems of education system in different cultures and roles of students and teachers. It also deals about cross-cultural similarities and differences in teaching and learning styles. The reading lessons are : School is bad for children by John Holt, How the web destroys the quality of students' research papers by David Rothenberg and an opposing view by Richard Cummins, Multiple intelligences and emotional intelligence by David Miller Sadker and Myra Pollack Sadker, The teacher who changes my life by Nicholas Gage, Let's tell the story of all American's cultures by Ji-Yeon Mary Yuhfill, Coyote and the crying song by Harold Courlander, First grade standing in the hall by Cheryl Savageau and humor and cartoon. The third chapter deals about use of technology and mass media which explores the content, functions of technology and the ways in which it shapes people's view themselves, others, and the world at large. The reading lessons are: Computers and the pursuit of happiness by David Gelernter and an opposing view by Winn F. Martin, We've got mail- always by Andrew Leonard, Propaganda techniques in today's advertising by Ann McClintock, Students shall not download, yeah, sure by Kate Zernike, Don't touch that dial by Madeline Drexler, Conceptual fruit by Thaisa Frank, All watched over by machines of loving grace by Richard 
Brautigan and humor and cartoon. The fourth chapter deals with gender and expectations associated with female and with male character, behavior, and appearance. It also deals about cultural and biological factors that shape attitudes toward gender and consequences of gender stereotyping and traditional and changing gender roles. The reading lessons are: Sex roles by Hamilton McCubbin and Barbara Blum Dahl, Boys will be boys by Barbara Kantrowitz and Claudia Kalb, Sex, sighs, and conversation by Deborah Tannen, Women have what it takes by Carol Barkalow and an opposing view by Bill Norton, The androgynous male by Noel Perrin, The princess and the admiral by Charlotte Pomerantz, The greater god by Rakesh Ratti and humor and cartoon. The fifth chapter deals with work that explores attitudes toward work and examine the reasons some individuals find their jobs enjoyable and rewarding and others do not. It also considers concepts of success- both professional and personality the qualities of an ideal job, and the notion of the American Dream. The reading lessons are: The new American dreamers by Ruth Sidel, Someone is stealing your life by Michael Ventura, Our schedules, our selves by Jay Walljasper, The rage to know by Horace Freeland Judson, Los Pobres by Richard Rodriguez, Action will be taken by Heinrich Boll, To be of use by Marge Piercy and humor and cartoon.

In addition to those, an informational section on writing skills, titled 'The Essential of Writing,' is placed between chapters two and three. It is printed in a different color so that it can be easily traced out. It contains essential information about writing and plentiful examples. Students are encouraged to go to the information whenever they have a writing assignment. The writing section is in three parts. The first part informed about the structure of an essay: introduction, body paragraph and the conclusion. The second part deals about the writing process: assigning the writing situation, exploring and planning, drafting, revising, editing, and proofreading. The third part explained about the writing with sources: types of sources, locating sources, evaluating sources, taking notes from sources, and documenting the sources for the writing purpose. The five thematic chapters can be presented as follows:

Chapter 1: Intercultural Communication

Main ideas and supporting details

Chapter 2: Education

Purpose and audience

Chapter 3: Mass Media and Technology

Figures of speech

Chapter 4: Gender Roles

Summarizing and paraphrasing

Chapter 5: Work

Tone 


\section{A Book Review: New Directions, Reading, Writing, and Critical Thinking}

The organization of all five chapters is very much systematic. Each chapter begins with a brief (chapter opener) introduction describing the major theme of the chapter, followed by a list of questions and quotations related to the readings. To raise awareness of, and interest in, the chapter topic, students discuss the questions and quotations in a small group and share personal opinions and experiences. There are three core reading lessons in each chapter containing a balance of academic and personal writing. The core readings have a full range of pre and post reading activities: journal writing, previewing the topic, agreeing and disagreeing, taking notes while reading, reading journal, guessing and discussing main ideas, reflecting on content, and vocabulary discussion. To make connection between reading lessons and the learners' life, there are given different making connection activities based on writing or discussion activity. The questions help students to synthesize the information presented in the core readings to combine facts, ideas, and belief to form their own opinions and judgments about issues. Students compare and contrast the authors' ideas and writing techniques, imagine, how the authors might respond to each other, and apply concepts discussed in one reading to another. Each chapter contains five additional readings (two prose pieces, a story, a poem, a joke) and a cartoon. These readings have only a few accompanying tasks. The teacher may use them to read inside the classroom or out of the classroom. The additional material allows students to explore issues in greater depth, to apply the writing technique learned earlier in the chapter, and to practice their intensive and extensive reading skills. The concluding section of each chapter presents five essay topics that require students to use various rhetorical strategies, such as compare and contrast, cause and effect, and division and classification, and higher-order thinking skills, especially synthesis, interpretation, and application. The assignments include expository, argumentative, and narrative writing. For each assignment, students support their ideas with reference to the chapter readings, library and Internet sources, and personal experience.

\section{Strengths and Weaknesses of the Book}

The book has got some strength as the textbook of Bachelor level learners in the context of Nepal under Tribhuvan University. The price of the book is affordable in our context (rupees 232only). The contents of the book are authentic; taken from real situation. The lessons are comprehensible which describe with pictorial presentation. There are given contextual questions to clarify the given lessons with the purpose of critical thinking. Some quotations are collected to share more information about the reading lessons.

The signpost questions are also given before reading the real texts which control the readers' mind make the learners to be attentive and encouraged to read the given text. The quality of the paper is also very nice especially cover page is very much attractive. This book has integrated reading, writing, speaking, and listening activities, students learn to generate hypothesis, argue, analyze critically, interpret a writer's meaning inferentially as well as literally, 
discriminate between opinion and fact, detect fallacies in reasoning, reach conclusions and judgments based on supportable criteria, and propose new ideas. The book also stresses the development of students' academic vocabulary. This takes students through the major stages of writing process (assessing the writing situation, exploring and planning, drafting, revising, editing and proof reading). The book suggests strategies that will help learners compose expository and argumentative essays and use sources effectively in researched writing. It provides many opportunities for formal and informal writing including journal entries, free writing, summaries, reports and essays. The diverse 35 reading topics selection and graphic material engage students in important social issues and promote a stimulating context for developing reading, writing and critical thinking skills. There are some notes taking task that students engage in while reading activity which develop reading and writing skill. A humor section for each chapter, with a thematically related joke and cartoon create fun in learning. It includes Internet and library activities to develop students' language and research skills. The book also contains one web -based activity per chapter in which students practice listening comprehension skills. In this book, there are more charts, graphs, and tables for practice in understanding numerical presentation of information.

Although, there are many strengths of this book, it has got some weaknesses; pictures are given but they are not sufficient to create context for the critical thinking. Some topics: more than two reading lessons give same ideas in all the chapters. The task for interpreting jokes is not given which is very much necessary to interpret jokes. Most of the texts are taken from Western World only few from the Eastern World. Only subjective types of questions are included in the exercise section, no objective types of questions are included as the exercise.

\section{Conclusion}

As a cocluding remarks it can be suggested that further improvements should be done for better attraction of this book. Sufficient pictures should be given in all reading lessons which help to develop creative thinking. The reading lessons which give similar ideas should be excluded from the book. There should be given exercise to interpret the jokes and cartoons. Some more texts should be taken from the Eastern World as maximum texts are taken from the Western World. It would be better to include some objective type of questions in the exercise section.

\section{References}

Fisher, A. (2011). Critical thinking: An introduction. Cambridge: CUP.

Gardner, P. S. (2005). New Directions: Reading, writing, and critical thinking. Cambridge: Cambridge University Press.

Khatri, D. K. (2010). A comprehensible handbook of reading, writing, and critical thinking. Kirtipur: New Hirabook Enterprises.

White, R., \& Arndt,V. (1991). Process writing. London: Longman. 